\title{
An Advanced Fuzzy Logic Based Method for Power Transformers Assessment
}

\author{
Si Huy Cuong Nguyen ${ }^{1, *}$, Thanh Phong Mai ${ }^{2}$ \\ ${ }^{1}$ Technical Department, Electric Testing Company, Ho Chi Minh City, Vietnam \\ ${ }^{2}$ Academic Affairs Department, Long An College, Tan An City, Vietnam
}

Email address:

nguyensihuycuong@gmail.com (Si H. C. Nguyen)

${ }^{*}$ Corresponding author

\section{To cite this article:}

Si Huy Cuong Nguyen, Thanh Phong Mai. An Advanced Fuzzy Logic Based Method for Power Transformers Assessment. American Journal of Electrical Power and Energy Systems. Vol. 10, No. 5, 2021, pp. 74-81. doi: 10.11648/j.epes.20211005.11

Received: August 28, 2021; Accepted: September 11, 2021; Published: September 26, 2021

\begin{abstract}
Dissolved Gas Analysis is an effective method for detecting faulty power transformers in their early stages. However, technical interpretation of results can be complex and highly dependent on the experience of experts. This paper presents an attempt to detect power transformer incipient fault via gas concentrations obtained from oil sampling and Dissolved Gas Analysis. The proposed method uses a sophisticated fuzzy logic system to perform fault type classification. Ratios and relative percentages of 5 key gases (Hydrogen, Methane, Ethane, Ethylene, and Acetylene) are taken as input variables, then the fuzzy system will try to generate an output vector that indicates six basic fault types, including partial, low, and high energy discharges as well as three ranges of thermal fault. This method can be easily implemented in any environment that supports basic mathematical operators. To demonstrate how the proposed fuzzy logic method works, the authors developed an offline MATLAB script and an online web-based application that can provide multiple assessments by various methods simultaneously. The set of membership functions and fuzzy rules presented in this paper allows the detection of multiple faults at once. Performance tests on many actual data sets show that the proposed method achieves better accuracy than the traditional ratio codes, even on a par with state-of-the-art graphical-based tools such as the Duval triangle or pentagon.
\end{abstract}

Keywords: Power Transformer, Incipient Fault Detection, Dissolved Gas Analysis, Fuzzy Logic

\section{Introduction}

In-service power transformers are frequently subjected to both potential internal defects and external stresses. Thermal stress caused by local overheating accelerates the aging process of oil and paper insulation. Electrical and mechanical stresses from external sources such as lightning strikes or short-circuit current greatly contribute to reducing the remaining lifetime of power transformers. Those stresses cause material decomposition and generate dissolved combustible gases in insulating oil, some of which are oxides of carbon, hydrogen, and hydrocarbons. Internal defects generate a particular amount of characteristic gases dissolved in insulating oil that can be used for early fault identification.

Proactive detection of faults helps minimize the risk of undesirable outage of power transformers from the power system network. Effective monitoring and diagnostic techniques must be adopted to improve the reliability of the equipment and to avoid any catastrophic failure. Among existing techniques, dissolved gas in oil analysis (DGA) is a powerful method to detect power transformer incipient faults [1-3].

Conventional DGA interpretation methods such as key gas inspection or gas ratios based methods [4-7] have been widely used, but they still have some limits and sometimes cannot give a proper diagnosis. Recently, the introduction of the Duval triangles and pentagons [8-10] solved the problem of unidentified faults. However, the analysis is not always straightforward as there may be more than one fault present at the same time. Precise DGA interpretation is still a hot topic in the power transformer fault diagnosis and condition assessment research area.

In this paper, a fuzzy logic-based method is developed to enhance the quality of existing DGA interpretation tools. While other methods can only detect a single fault, the fuzzy 
method is feasible to address the classification of transformer faults in the case where multiple faults occur at once. Since fuzzy logic has an advantage in processing unclear states, it is also possible to implement the criticality alert in the fuzzy diagnostic system. At the end of this paper, the authors would like to compare the efficiency of the fuzzy logic-based approach to other conventional methods by surveying real cases in Vietnam.

\section{Literature Review}

Interpretation of DGA results is not always straightforward, as there are several possible causes of the presence of gas in a transformer. Some of those are related to real fault conditions, others are related to more benign conditions such as stray gassing. There is no direct and infallible method using DGA to obtain an exact evaluation of a transformer's condition. However, it is necessary to have a reliable DGA assessment tool to detect any possible fault that might occur inside a power transformer. In this section, the authors wish to provide a brief review of popular DGA interpretation techniques and point out the reason why a fuzzy logic-based method can provide a better solution.

\subsection{Key Gas Inspection}

The key gas method applies some basic rules for finding the fault pattern based on dominant gases. Hydrogen $\left(\mathrm{H}_{2}\right)$ is primarily generated from corona partial discharge; Acetylene $\left(\mathrm{C}_{2} \mathrm{H}_{2}\right)$ is created from arcing in oil or paper at very high temperatures. Overheating and thermal faults give rise to Methane $\left(\mathrm{CH}_{4}\right)$, Ethane $\left(\mathrm{C}_{2} \mathrm{H}_{6}\right)$, and Ethylene $\left(\mathrm{C}_{2} \mathrm{H}_{4}\right)$ as well as Carbon Monoxide (CO), and Carbon Dioxide $\left(\mathrm{CO}_{2}\right)$ if the fault is related to solid insulation decomposition. By determining which gasses are dominating, one can speculate the existence of internal fault.

There is one big challenge in using this method, as it requires the users' experience. Furthermore, software implementation of the key gas method seems to be a challenge. Inconclusive or wrong fault identification occurs regularly even with sophisticated key gas rules. The reason for this problem is that it is not always clear which is the dominant gas, or the main gas formed may not be reliable enough for fault identification. However, observing key gases is essential for building an advanced interpretation system based on fuzzy logic or artificial intelligence.

Table 1. Fault identification based on key gasses.

\begin{tabular}{ll}
\hline Fault & Key gasses \\
\hline Partial discharge & $\mathrm{H}_{2}$ \\
Arcing & $\mathrm{C}_{2} \mathrm{H}_{2}$ \\
Thermal fault (oil) & $\mathrm{CH}_{4}, \mathrm{C}_{2} \mathrm{H}_{4}, \mathrm{C}_{2} \mathrm{H}_{6}$ \\
Thermal fault (paper) & $\mathrm{CO}, \mathrm{CO}_{2}$ \\
\hline
\end{tabular}

\subsection{Gas Ratio Methods}

Gas ratio-based methods take correlation of ratio between some pairs of fault gas concentrations with certain fault types. These methods were introduced in the 1970s and remain popular until lately. There are several variations such as the Dornenburg ratio, the Rogers ratio, and the three gas ratio methods [3-7].

The Rogers ratio method [4] considers two of the four ratios $\mathrm{CH}_{4} / \mathrm{H}_{2}, \mathrm{C}_{2} \mathrm{H}_{2} / \mathrm{C}_{2} \mathrm{H}_{4}, \mathrm{C}_{2} \mathrm{H}_{4} / \mathrm{C}_{2} \mathrm{H}_{6}$, and $\mathrm{C}_{2} \mathrm{H}_{6} / \mathrm{CH}_{4}$. However, later studies showed the ratio of $\mathrm{C}_{2} \mathrm{H}_{6} / \mathrm{CH}_{4}$ did not correlate well with the faults, and thus it was removed in recent studies. The three ratio method is now recommended by both the IEEE and the IEC standards $[3,5]$. The interpretation guide of this method is shown in tables 1 and 2, in which there are three ratio codes for each ratio and six fault types [6].

Dividing one small value of a fault gas by another small value of another fault gas will give a significant ratio, but the magnitudes of the fault gases in such cases are too small. For that reason, ratio methods are only applicable when a significant amount of the gas is present; otherwise, they may lead to misdiagnosis. The common weakness of ratio-based methods is that they sometimes are not capable of giving a result or may yield an incorrect one in others. Therefore, some researchers attempt to add or modify rules to achieve better accuracy [11].

Table 2. The IEC ratio codes [6].

\begin{tabular}{llll}
\hline \multirow{2}{*}{ Ratio } & \multicolumn{3}{l}{ States } \\
\cline { 2 - 4 } & $\mathbf{0}$ & $\mathbf{1}$ & $\mathbf{2}$ \\
\hline $\mathrm{r}_{1}=\mathrm{C}_{2} \mathrm{H}_{2} / \mathrm{C}_{2} \mathrm{H}_{4}$ & $<0.1$ & $0.1-3$ & $>3$ \\
$\mathrm{r}_{2}=\mathrm{CH}_{4} / \mathrm{H}_{2}$ & $0.1-1$ & $<0.1$ & $>1$ \\
$\mathrm{r}_{3}=\mathrm{C}_{2} \mathrm{H}_{4} / \mathrm{C}_{2} \mathrm{H}_{6}$ & $<1$ & $1-3$ & $>3$ \\
\hline
\end{tabular}

Table 3. Fault classification by using the IEC ratio codes [6].

\begin{tabular}{lllll}
\hline Fault & $\begin{array}{l}\text { Fault } \\
\text { Code }\end{array}$ & $\mathbf{r}_{1}$ & $\mathbf{r}_{2}$ & $\mathbf{r}_{3}$ \\
\hline Normal & $\mathrm{N}$ & 0 & 0 & 0 \\
Partial discharge & PD & 0 or 1 & 1 & 0 \\
Low energy discharge & $\mathrm{D} 1$ & 1 or 2 & 0 & 1 or 2 \\
High energy discharge & $\mathrm{D} 2$ & 1 & 0 & 2 \\
Thermal fault with $\mathrm{t}<150^{\circ} \mathrm{C}$ & $\mathrm{T} 1$ & 0 & 0 & 1 \\
Thermal fault with $150^{\circ} \mathrm{C}<\mathrm{t}<300^{\circ} \mathrm{C}$ & & 0 & 2 & 0 \\
Thermal fault with $300^{\circ} \mathrm{C}<\mathrm{t}<700^{\circ} \mathrm{C}$ & $\mathrm{T} 2$ & 0 & 2 & 1 \\
Thermal fault with $\mathrm{t}>700^{\circ} \mathrm{C}$ & $\mathrm{T} 3$ & 0 & 2 & 2 \\
\hline
\end{tabular}

\subsection{Graphical Methods}

Several graphical methods have been developed to overcome the problem of having unidentified cases. Two of the most well-known graphical-based methods are the Duval triangles and pentagons [8-10]. Other approaches such as the Mansour diagnostic pentagon [12] or the heptagon developed by Gouda et al. [13] were introduced recently. In this section, the authors shall only briefly summarize the Duval triangles and pentagons, as they are used for comparison later in the research.

\subsubsection{Duval Triangles}

The original Duval triangle [8] uses a set of three characteristics gases: $\mathrm{CH}_{4}, \mathrm{C}_{2} \mathrm{H}_{4}$, and $\mathrm{C}_{2} \mathrm{H}_{2}$. The sides of the triangle are expressed in triangular coordinates $(\mathrm{x}, \mathrm{y}, \mathrm{z})$, where $\mathrm{x}, \mathrm{y}, \mathrm{z}$ are the relative percentage of $\mathrm{CH}_{4}, \mathrm{C}_{2} \mathrm{H}_{4}$, and $\mathrm{C}_{2} \mathrm{H}_{2}$, respectively. 
This method allows the identification of the six basic types of faults mentioned in the last section (PD, D1, D2, T1, T2, and T3), in addition to mixtures of electrical/ thermal faults in zone DT. Those regions are established through empirical inspection of DGA results from a specific liquid type and the observed equipment gassing source. A fault is identified based on which region the corresponding point $(\mathrm{x}, \mathrm{y}, \mathrm{z})$ lies on.

To this day, there are several versions of the Duval triangle, in which the first, fourth and fifth are exclusive to mineral oil. The fourth and fifth triangles take a different set of gases and are only used for thermal fault inspection [9]. The first triangle, together with the pentagon counterpart, as depicted in figure 1 , are widely used for the diagnosis of high voltage power transformers.

\subsubsection{Duval Pentagon}

The Duval pentagon [10] uses the percentages of five gases $\left(\mathrm{H}_{2}, \mathrm{CH}_{4}, \mathrm{C}_{2} \mathrm{H}_{6}, \mathrm{C}_{2} \mathrm{H}_{4}\right.$, and $\left.\mathrm{C}_{2} \mathrm{H}_{2}\right)$ to their sum. The vertices of this pentagon correspond to the maximum relative concentration of $40 \%$. Inside this pentagon, the zones are corresponding to the basic types of faults just like that of the Duval triangle, as well as a stray gassing zone (S). The percentage of each gas is marked on the appropriate axis drawn from the center of the pentagon to one of the vertices. These points are then connected to form a small polygon in which the centroid always lies inside the Duval pentagon. The position of the designated centroid points to one of the seven fault zones as one can observe in figure 1 .

Both Duval methods use relative gas percentages instead of ratios and thus avoid the problem of unidentified cases. In contrast, because the triangles and pentagons always give a diagnostic, they should only be used to identify a fault when a sufficient amount of combustible gas exists. Moreover, due to the nature of graphical-based interpretation methods, they cannot verify the existence of multiple faults at a time.

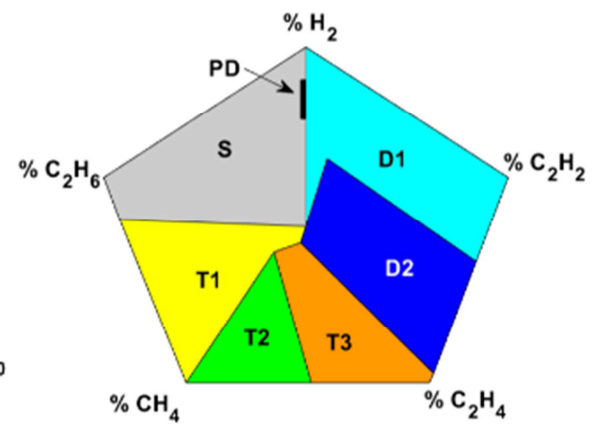

Figure 1. The Duval triangle (left) and pentagon (right).

\section{Proposed Method}

When one or more than one fault occurs in a transformer, multiple key gases with different concentrations exist and cause the ratio codes to overlap. Because of that, the relationship between various gases becomes too complicated and may not match the predefined values. In multiple-fault conditions, gases from different faults are mixed, resulting in confusing ratios between gas components. This problem can be overcome with the aid of more sophisticated analysis methods such as the fuzzy logic presented in this section. The proposed method is called Fuzzy Ratio and Percentage (FRP in short).

\subsection{Fuzzy Logic Based Method}

In the IEC ratio-based interpretation methods, the ratio codes 0,1 , or 2 can either be True or False, but not anything in between. The gas ratio boundary should be fuzzy, especially when more than one type of fault exists. Between different kinds of faults, the codes should not change sharply across their boundaries. Therefore, in the proposed fuzzy logic-based method, input variables are transformed into a set of states via fuzzy functions. Membership functions in the uppermost region are S-shape functions governed by (1), while counterparts in the lowest region are Z-shape curves represented by (2). The middle region is occupied by $\pi$-shape curves calculated by the minimum combinations of (1) and (2). In these equations, a, b, c, and d are parameters that affect the shape and boundary of the curve. They represent the boundary conditions so that the membership functions translate input values into intermittent fuzzy states.

$$
\begin{gathered}
\mu_{s}(x ; a, b)=\left\{\begin{array}{c}
0, x \leq a \\
2\left(\frac{x-a}{b-a}\right)^{2}, a \leq x \leq \frac{a+b}{2} \\
1-2\left(\frac{x-b}{b-a}\right)^{2}, \frac{a+b}{2} \leq x \leq b \\
1, x \geq b \\
1, x \leq c
\end{array}\right. \\
\mu_{z}(x ; c, d)=\left\{\begin{array}{r}
1-2\left(\frac{x-c}{d-c}\right)^{2}, c \leq x \leq \frac{c+d}{2} \\
2\left(\frac{x-d}{d-c}\right)^{2}, \frac{c+d}{2} \leq x \leq d \\
0, x \geq d
\end{array}\right.
\end{gathered}
$$

Conditional statements given by the rules in table 2 are combinations of conventional logics "AND" and "OR", which can be converted into mathematical terms by the "MIN" and "MAX" operators. For example, the last rule is $\left[r_{1}\right.$ is 0] AND [ $r_{2}$ is 2] AND [ $r_{3}$ is 2]; this statement is translated to $\min \left[\mu_{\mathrm{s}}\left(\mathrm{r}_{1}\right), \mu_{\mathrm{z}}\left(\mathrm{r}_{2}\right), \mu_{\mathrm{z}}\left(\mathrm{r}_{3}\right)\right]$. When a condition is fulfilled, either fully or partially, certain rules will be triggered. If the output is defined by a vector in which each 
index corresponds to a fault code, then those rules will give values in the range between 0 and 1 to the indexes based on the trigger condition. This method allows the detection of multiple faults at once, a feature that neither the conventional gas ratio methods nor the Duval methods had.

\subsection{Fuzzy Rules Based on Gas Ratio}

Initially, membership functions and fuzzy rules were designed based on the IEC gas ratio method. However, this approach turned out to be the same as the conventional method; that means the weakness of having unidentified cases still exists. After inspecting various samples, the authors developed an improved set of ratio codes through membership functions shown in table 4 . The corresponding fuzzy rules are described in table 5 , in which $F_{r}$ is the output vector consists of 7 indexes correspond to six basic types of faults (PD, D1, D2, T1, T2, T3) and a normal state (N).

Table 4. Gas ratio membership functions.

\begin{tabular}{llllll}
\hline Membership function & Type & a & b & c & d \\
\hline$\mu_{\mathrm{r} 10}\left(\mathrm{r}_{1}\right)$ & Z-shape & - & - & 0.3 & 0.7 \\
$\mu_{\mathrm{r} 11}\left(\mathrm{r}_{1}\right)$ & П-shape & 0.3 & 0.7 & 2.8 & 3.2 \\
$\mu_{\mathrm{r} 12}\left(\mathrm{r}_{1}\right)$ & П-shape & 2.8 & 3.2 & 9.8 & 10.2 \\
$\mu_{\mathrm{r} 13}\left(\mathrm{r}_{1}\right)$ & S-shape & 9.8 & 10.2 & - & - \\
$\mu_{\mathrm{r} 20}\left(\mathrm{r}_{2}\right)$ & П-shape & 0 & 0.4 & 0.8 & 1.2 \\
$\mu_{\mathrm{r} 21}\left(\mathrm{r}_{2}\right)$ & Z-shape & - & - & 0 & 0.4 \\
$\mu_{\mathrm{r} 22}\left(\mathrm{r}_{2}\right)$ & П-shape & 0.8 & 1.2 & 2.8 & 3.2 \\
$\mu_{\mathrm{r} 23}\left(\mathrm{r}_{2}\right)$ & S-shape & 2.8 & 3.2 & - & - \\
$\mu_{\mathrm{r} 30}\left(\mathrm{r}_{3}\right)$ & Z-shape & - & - & 0.8 & 1.2 \\
$\mu_{\mathrm{r} 31}\left(\mathrm{r}_{3}\right)$ & П-shape & 0.8 & 1.2 & 2.8 & 3.2 \\
$\mu_{\mathrm{r} 32}\left(\mathrm{r}_{3}\right)$ & S-shape & 2.8 & 3.2 & - & - \\
\hline
\end{tabular}

Table 5. Gas ratios fuzzy rules.

\begin{tabular}{|c|c|}
\hline Fault & Rule \\
\hline Normal & $\mathrm{F}_{\mathrm{r}}(0)=\min \left[\mu_{\mathrm{r} 10}\left(\mathrm{r}_{1}\right), \mu_{\mathrm{r} 20}\left(\mathrm{r}_{2}\right), \mu_{\mathrm{r} 30}\left(\mathrm{r}_{3}\right)\right]$ \\
\hline \multirow[t]{3}{*}{ PD } & $\mathrm{F}_{\mathrm{r}}(1)=\min \left[\max \left[\mu_{\mathrm{r} 10}\left(\mathrm{r}_{1}\right), \mu_{\mathrm{r} 11}\left(\mathrm{r}_{1}\right)\right], \mu_{\mathrm{r} 21}\left(\mathrm{r}_{2}\right)\right]$ \\
\hline & $\mathrm{F}_{\mathrm{r}}(2)=\max \left[\mathrm{d}_{11}, \mathrm{~d}_{12}, \mathrm{~d}_{13}, \mathrm{~d}_{14}\right]$ \\
\hline & Where: \\
\hline \multirow[t]{4}{*}{ D1 } & $\begin{array}{l}\mathrm{d}_{11}=\min \left[\mu_{\mathrm{r} 11}\left(\mathrm{r}_{1}\right), \mu_{\mathrm{r} 21}\left(\mathrm{r}_{2}\right), \mu_{\mathrm{r} 30}\left(\mathrm{r}_{3}\right)\right] \\
\mathrm{d}_{12}=\min \left[\max \left[\mu_{\mathrm{r} 10}\left(\mathrm{r}_{1}\right), \mu_{\mathrm{r} 11}\left(\mathrm{r}_{1}\right)\right], \mu_{\mathrm{r} 21}\left(\mathrm{r}_{2}\right), \mu_{\mathrm{r} 31}\left(\mathrm{r}_{3}\right)\right]\end{array}$ \\
\hline & $\mathrm{d}_{13}=\min \left[\mu_{\mathrm{r} 11}\left(\mathrm{r}_{1}\right), \max \left[\mu_{\mathrm{r} 20}\left(\mathrm{r}_{2}\right), \mu_{\mathrm{r} 22}\left(\mathrm{r}_{2}\right), \mu_{\mathrm{r} 23}\left(\mathrm{r}_{2}\right)\right], \max \left[\mu_{\mathrm{r} 30}\left(\mathrm{r}_{3}\right), \mu_{\mathrm{r} 31}\left(\mathrm{r}_{3}\right)\right]\right]$ \\
\hline & $\mathrm{d}_{14}=\min \left[\mu_{\mathrm{r} 12}\left(\mathrm{r}_{1}\right), \max \left[\mu_{\mathrm{r} 20}\left(\mathrm{r}_{2}\right), \mu_{\mathrm{r} 21}\left(\mathrm{r}_{2}\right), \mu_{\mathrm{r} 22}\left(\mathrm{r}_{2}\right)\right], \mu_{\mathrm{r} 31}\left(\mathrm{r}_{3}\right)\right]$ \\
\hline & $\mathrm{F}_{\mathrm{r}}(3)=\max \left[\mathrm{d}_{21}, \mathrm{~d}_{22}, \mathrm{~d}_{23}, \mathrm{~d}_{24}\right]$ \\
\hline \multirow[t]{3}{*}{ D2 } & $\begin{array}{l}\text { Where: } \\
\mathrm{d}_{21}=\min \left[\max \left[\mu_{\mathrm{r} 10}\left(\mathrm{r}_{1}\right), \mu_{\mathrm{r} 11}\left(\mathrm{r}_{1}\right)\right], \mu_{\mathrm{r} 21}\left(\mathrm{r}_{2}\right), \mu_{\mathrm{r} 32}\left(\mathrm{r}_{3}\right)\right] \\
\mathrm{d}_{22}=\min \left[\mu_{\mathrm{r} 11}\left(\mathrm{r}_{1}\right), \max \left[\mu_{\mathrm{r} 20}\left(\mathrm{r}_{2}\right), \mu_{\mathrm{r} 22}\left(\mathrm{r}_{2}\right), \mu_{\mathrm{r} 23}\left(\mathrm{r}_{2}\right)\right], \mu_{\mathrm{r} 32}\left(\mathrm{r}_{3}\right)\right] \\
\mathrm{d}_{23}=\min \left[\mu_{\mathrm{r} 12}\left(\mathrm{r}_{1}\right), \max \left[\mu_{\mathrm{r} 20}\left(\mathrm{r}_{2}\right), \mu_{\mathrm{r} 21}\left(\mathrm{r}_{2}\right), \mu_{\mathrm{r} 22}\left(\mathrm{r}_{2}\right)\right], \max \left[\mu_{\mathrm{r} 30}\left(\mathrm{r}_{3}\right), \mu_{\mathrm{r} 32}\left(\mathrm{r}_{3}\right)\right]\right] \\
d_{24}=\mu_{\mathrm{r} 13}\left(\mathrm{r}_{1}\right)\end{array}$ \\
\hline & $\mathrm{F}_{\mathrm{r}}(4)=\max \left[\mathrm{t}_{11}, \mathrm{t}_{12}, \mathrm{t}_{13}\right]$ \\
\hline & Where: \\
\hline \multirow[t]{4}{*}{ T1 } & $\mathrm{t}_{11}=\min \left[\mu_{\mathrm{r} 10}\left(\mathrm{r}_{1}\right), \mu_{\mathrm{r} 20}\left(\mathrm{r}_{2}\right), \mu_{\mathrm{r} 31}\left(\mathrm{r}_{3}\right)\right]$ \\
\hline & $\mathrm{t}_{12}=\min \left[\mu_{\mathrm{r} 10}\left(\mathrm{r}_{1}\right), \max \left[\mu_{\mathrm{r} 22}\left(\mathrm{r}_{2}\right), \mu_{\mathrm{r} 23}\left(\mathrm{r}_{2}\right)\right], \mu_{\mathrm{r} 30}\left(\mathrm{r}_{3}\right)\right]$ \\
\hline & $\mathrm{t}_{13}=\min \left[\mu_{\mathrm{r} 12}\left(\mathrm{r}_{1}\right), \mu_{\mathrm{r} 23}\left(\mathrm{r}_{2}\right), \mu_{\mathrm{r} 30}\left(\mathrm{r}_{3}\right)\right]$ \\
\hline & $\mathrm{F}_{\mathrm{r}}(5)=\max \left[\mathrm{t}_{21}, \mathrm{t}_{22}\right]$ \\
\hline \multirow{5}{*}{$\mathrm{T} 2$} & Where, \\
\hline & $\mathrm{t}_{21}=\min \left[\mu_{\mathrm{r} 10}\left(\mathrm{r}_{1}\right), \max \left[\mu_{\mathrm{r} 22}\left(\mathrm{r}_{2}\right), \mu_{\mathrm{r} 23}\left(\mathrm{r}_{2}\right)\right], \mu_{\mathrm{r} 31}\left(\mathrm{r}_{3}\right)\right]$ \\
\hline & $\mathrm{t}_{22}=\min \left[\mu_{\mathrm{r} 12}\left(\mathrm{r}_{1}\right), \mu_{\mathrm{r} 23}\left(\mathrm{r}_{2}\right), \mu_{\mathrm{r} 31}\left(\mathrm{r}_{3}\right)\right]$ \\
\hline & $\mathrm{F}_{\mathrm{r}}(6)=\max \left[\mathrm{t}_{31}, \mathrm{t}_{32}, \mathrm{t}_{33}\right]$ \\
\hline & Where: \\
\hline \multirow[t]{3}{*}{$\mathrm{T} 3$} & $\mathrm{t}_{31}=\min \left[\mu_{\mathrm{r} 10}\left(\mathrm{r}_{1}\right), \mu_{\mathrm{r} 20}\left(\mathrm{r}_{2}\right), \mu_{\mathrm{r} 32}\left(\mathrm{r}_{3}\right)\right]$ \\
\hline & $\mathrm{t}_{32}=\min \left[\mu_{\mathrm{r} 10}\left(\mathrm{r}_{1}\right), \max \left[\mu_{\mathrm{r} 22}\left(\mathrm{r}_{2}\right), \mu_{\mathrm{r} 23}\left(\mathrm{r}_{2}\right)\right], \mu_{\mathrm{r} 32}\left(\mathrm{r}_{3}\right)\right]$ \\
\hline & $\mathrm{t}_{33}=\min \left[\mu_{\mathrm{r} 12}\left(\mathrm{r}_{1}\right), \mu_{\mathrm{r} 23}\left(\mathrm{r}_{2}\right), \mu_{\mathrm{r} 32}\left(\mathrm{r}_{3}\right)\right]$ \\
\hline
\end{tabular}

\subsection{Fuzzy Rules Based on Gas Percentage}

Performance test on the gas ratio-based fuzzy system shows an improvement in diagnostic accuracy. However, in some partial discharge cases, the Hydrogen contents are dominant, while other gases are insignificant. In those cases, the "Normal" rule is triggered instead of "PD", regardless of high $\mathrm{H}_{2}$ concentrations. It is not uncommon to find increased levels of $\mathrm{H}_{2}$ or $\mathrm{C}_{2} \mathrm{H}_{4}$ when $\mathrm{C}_{2} \mathrm{H}_{2}$ is detected, leading to a fuzzy boundary between low and high energy discharge faults. In that situation, the gas percentage method may be more effective and therefore, should be adopted to support the fuzzy gas ratio.
The relative percentages of $\mathrm{H}_{2}, \mathrm{CH}_{4}, \mathrm{C}_{2} \mathrm{H}_{6}, \mathrm{C}_{2} \mathrm{H}_{4}, \mathrm{C}_{2} \mathrm{H}_{2}$ in a sample are denoted as $p_{1}, p_{2}, p_{3}, p_{4}, p_{5}$. They are described in 3 levels: "Low", "Medium, and "High" by the Z, $\pi$, and S functions, just like their gas ratio counterparts. The boundary values of those functions the gas percentage fuzzy rules are mathematically described in the next two tables.

\subsection{Output Calculation}

By observation during performance tests, the authors realized that the gas ratio fuzzy system was more sensitive to thermal faults, while the gas percentage fuzzy system was more reliable in detecting partial discharge and low energy discharge faults. Therefore, the total fault vector should be 
calculated by taking the normalized average of the gas ratio and the gas percentage fuzzy outputs by (3).

$$
F_{\text {total }}=w_{r} \frac{F_{r}}{\sum_{i=0}^{6} F_{r}(i)}+w_{p} \frac{F_{p}}{\sum_{i=0}^{6} F_{p}(i)}
$$

Table 6. Gas percentage membership functions.

\begin{tabular}{llllll}
\hline Membership function & Type & a & b & c & d \\
\hline$\mu_{\mathrm{L}}($ gas \%) & Z-shape & - & - & 0 & 10 \\
$\mu_{\mathrm{M}}($ gas \%) & П-shape & 0 & 10 & 15 & 25 \\
$\mu_{\mathrm{H}}($ gas \%) & S-shape & 15 & 25 & - & - \\
\hline
\end{tabular}

Table 7. Gas percentage fuzzy rules.

\begin{tabular}{ll}
\hline Fault & Rule \\
\hline Normal & $\mathrm{F}_{\mathrm{p}}(0)=\min \left[\mu_{\mathrm{L}}\left(\mathrm{p}_{1}\right), \mu_{\mathrm{L}}\left(\mathrm{p}_{2}\right), \mu_{\mathrm{L}}\left(\mathrm{p}_{3}\right), \mu_{\mathrm{L}}\left(\mathrm{p}_{4}\right), \mu_{\mathrm{L}}\left(\mathrm{p}_{5}\right)\right]$ \\
PD & $\mathrm{F}_{\mathrm{p}}(1)=\min \left[\mu_{\mathrm{H}}\left(\mathrm{p}_{1}\right), \max \left[\mu_{\mathrm{L}}\left(\mathrm{p}_{3}\right), \mu_{\mathrm{M}}\left(\mathrm{p}_{3}\right)\right], \mu_{\mathrm{L}}\left(\mathrm{p}_{4}\right), \mu_{\mathrm{L}}\left(\mathrm{p}_{5}\right)\right]$ \\
D1 & $\mathrm{F}_{\mathrm{p}}(2)=\min \left[\max \left[\mu_{\mathrm{M}}\left(\mathrm{p}_{1}\right), \mu_{\mathrm{H}}\left(\mathrm{p}_{1}\right)\right], \mu_{\mathrm{M}}\left(\mathrm{p}_{5}\right)\right]$ \\
D2 & $\mathrm{F}_{\mathrm{p}}(3)=\mu_{\mathrm{H}}\left(\mathrm{p}_{5}\right)$ \\
T1 & $\mathrm{F}_{\mathrm{p}}(4)=\min \left[\mu_{\mathrm{H}}\left(\mathrm{p}_{3}\right), \mu_{\mathrm{L}}\left(\mathrm{p}_{4}\right), \mu_{\mathrm{L}}\left(\mathrm{p}_{5}\right)\right]$ \\
T2 & $\mathrm{F}_{\mathrm{p}}(5)=\min \left[\max \left[\mu_{\mathrm{M}}\left(\mathrm{p}_{4}\right), \mu_{\mathrm{H}}\left(\mathrm{p}_{4}\right)\right], \mu_{\mathrm{L}}\left(\mathrm{p}_{5}\right)\right]$ \\
T3 & $\mathrm{F}_{\mathrm{p}}(6)=\min \left[\mu_{\mathrm{L}}\left(\mathrm{p}_{3}\right), \mu_{\mathrm{H}}\left(\mathrm{p}_{4}\right), \mu_{\mathrm{L}}\left(\mathrm{p}_{5}\right)\right]$ \\
\hline
\end{tabular}

* p1, p2, p3, p4, p5 are the percentages of $\mathrm{H}_{2}, \mathrm{CH}_{4}, \mathrm{C}_{2} \mathrm{H}_{6}, \mathrm{C}_{2} \mathrm{H}_{4}$ and $\mathrm{C}_{2} \mathrm{H}_{2}$
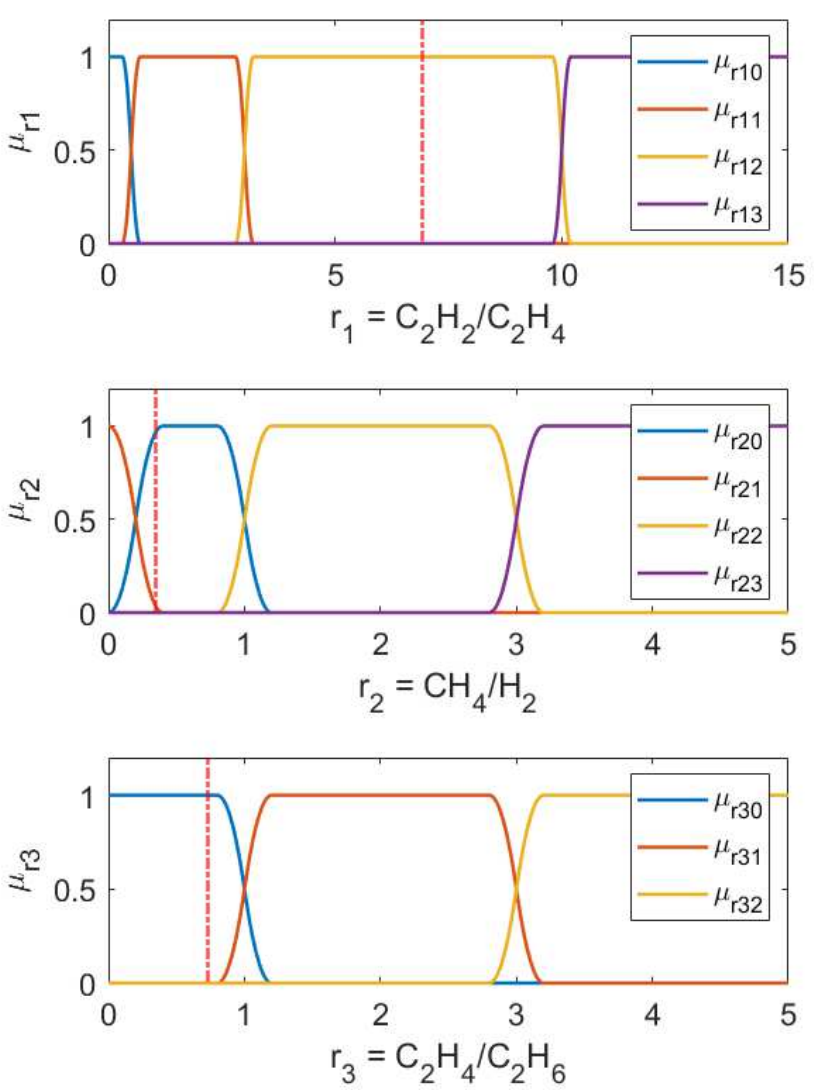

Figure 2. Fuzzy gas ratio membership functions of the given example.

This example illustrates in detail how the proposed method works. Consider a case where gas contents are: $\mathrm{H}_{2}$ $=63 \mathrm{ppm}, \mathrm{CH}_{4}=22 \mathrm{ppm}, \mathrm{C}_{2} \mathrm{H}_{6}=15 \mathrm{ppm}, \mathrm{C}_{2} \mathrm{H}_{4}=11 \mathrm{ppm}$ and $\mathrm{C}_{2} \mathrm{H}_{2}=76 \mathrm{ppm}$. The gas ratios are $\mathrm{r}_{1}=6.9, \mathrm{r}_{2}=0.35$, and $r_{3}=0.73$. This combination results in a ratio code of "200" that does not belong to the original IEC guideline.
The ratios are translated to fuzzy states (illustrated in figure 2):

1) $\left[\mu_{\mathrm{r} 10}\left(\mathrm{r}_{1}\right), \mu_{\mathrm{r} 11}\left(\mathrm{r}_{1}\right), \mu_{\mathrm{r} 12}\left(\mathrm{r}_{1}\right), \mu_{\mathrm{r} 13}\left(\mathrm{r}_{1}\right)\right]=[0,0,1,0]$;

2) $\left[\mu_{\mathrm{r} 20}\left(\mathrm{r}_{2}\right), \mu_{\mathrm{r} 21}\left(\mathrm{r}_{2}\right), \mu_{\mathrm{r} 22}\left(\mathrm{r}_{2}\right), \mu_{\mathrm{r} 23}\left(\mathrm{r}_{2}\right)\right]=[0.97,0.03,0,0]$;

3) $\left[\mu_{\mathrm{r} 30}\left(\mathrm{r}_{3}\right), \mu_{\mathrm{r} 31}\left(\mathrm{r}_{3}\right), \mu_{\mathrm{r} 32}\left(\mathrm{r}_{3}\right)=[1,0,0]\right.$.

This combination results in $\mathrm{F}_{\mathrm{r}}(3)$ equal to 0.97 and triggers the $\mathrm{D} 2$ fault rule. In this case, the fuzzy gas ratio rules in table 5 give a ratio diagnosis vector $F_{r}=[0,0,0$, $0.97,0,0,0]$. Similarly, the gas percentages are $\mathrm{p}_{1}=33.7 \%$, $\mathrm{p}_{2}=11.76 \%, \mathrm{p}_{3}=8.02 \%, \mathrm{p}_{4}=5.88 \%, \mathrm{p}_{5}=40.64 \%$. They are translated to:

1) $\left[\mu_{\mathrm{L}}\left(\mathrm{p}_{1}\right), \mu_{\mathrm{M}}\left(\mathrm{p}_{2}\right), \mu_{\mathrm{H}}\left(\mathrm{p}_{1}\right)\right]=[0,0,1]$;

2) $\left[\mu_{\mathrm{L}}\left(\mathrm{p}_{2}\right), \mu_{\mathrm{M}}\left(\mathrm{p}_{2}\right), \mu_{\mathrm{H}}\left(\mathrm{p}_{2}\right)\right]=[0,1,0]$;

3) $\left[\mu_{\mathrm{L}}\left(\mathrm{p}_{3}\right), \mu_{\mathrm{M}}\left(\mathrm{p}_{3}\right), \mu_{\mathrm{H}}\left(\mathrm{p}_{3}\right)=[0.08,0.92,0]\right.$;

4) $\left[\mu_{\mathrm{L}}\left(\mathrm{p}_{4}\right), \mu_{\mathrm{M}}\left(\mathrm{p}_{4}\right), \mu_{\mathrm{H}}\left(\mathrm{p}_{4}\right)=[0.08,0.66,0]\right.$;

5) $\left[\mu_{\mathrm{L}}\left(\mathrm{p}_{5}\right), \mu_{\mathrm{M}}\left(\mathrm{p}_{5}\right), \mu_{\mathrm{H}}\left(\mathrm{p}_{5}\right)\right]=[0,0,1]$.

The condition of D2 is fulfilled and thus $F_{p}(3)$ equal to 1 . The gas percentage laws in table 7 result in $\mathrm{F}_{\mathrm{p}}=[0,0,0,1,0$, $0,0]$. By using (3), the total output vector is $[0,0,0,1,0,0$, $0]$, which indicates occurrence of high energy discharge (D2) with $100 \%$ certainty.

\section{Results and Discussion}

The authors built a script in the MATLAB software environment to perform DGA interpretations of several datasets. The code consists of multiple methods, including Rogers ratio, IEC ratio, Duval triangle and pentagon, and the proposed fuzzy logic system. Results from all of those methods are compared with one another to evaluate their efficiency in incipient fault classification.

\subsection{Cases Study}

To test the performance of the proposed Fuzzy Ratio and Percentage method, the dataset obtained from [14] was used. There are 20 samples described in table 9; results obtained from multiple analyses are also compared. The proposed method outperforms traditional ratio codes in fault diagnosis capability. With this dataset, the proposed method generally agrees with the Duval triangle and pentagon, even achieves better accuracy in the tricky cases of partial discharge.

Another sample dataset was obtained from the Long An Power Company in Vietnam to investigate the performance of the proposed method. The performances of multiple methods are compared in table 9. One can observe that with such low gas concentrations, fault classification, in this case, would be tricky. With this dataset, all method generally agrees with one another. There is one tricky case with sample number 4 , which has dominant $\mathrm{H}_{2}$ and $\mathrm{CH}_{4}$ contents. This is an obvious sign of partial discharge. However, except for the proposed method, none of the others can classify this fault.

Multiple tests on different datasets [11, 15] were also performed but not fully show in this paper. In general, the proposed method generated highly reliable conclusions that agreed well with actual faults. 
Table 8. Dataset used for performance check [14] (gas contents in ppm).

\begin{tabular}{|c|c|c|c|c|c|c|c|c|c|c|c|}
\hline Sample & $\mathbf{H}_{2}$ & $\mathrm{CH}_{4}$ & $\mathrm{C}_{2} \mathrm{H}_{6}$ & $\mathrm{C}_{2} \mathrm{H}_{4}$ & $\mathrm{C}_{2} \mathrm{H}_{2}$ & $\begin{array}{l}\text { Known } \\
\text { fault [14] }\end{array}$ & $\begin{array}{l}\text { IEC } \\
{[5]}\end{array}$ & $\begin{array}{l}\text { Rogers } \\
{[4]}\end{array}$ & $\begin{array}{l}\text { Duval triangle } \\
\text { [8] }\end{array}$ & $\begin{array}{l}\text { Duval pentagon } \\
{[10]}\end{array}$ & Proposed method \\
\hline 1 & 200 & 700 & 250 & 740 & 1 & $\mathrm{~T} 2$ & $\mathrm{~T} 2$ & - & $\mathrm{T} 3$ & $\mathrm{~T} 3$ & $\begin{array}{l}\text { T2: } 84 \% \\
\text { T3: } 16 \%\end{array}$ \\
\hline 2 & 300 & 490 & 180 & 360 & 95 & $\mathrm{~T} 2$ & - & $\mathrm{T} 2$ & DT & $\mathrm{T} 3$ & $\begin{array}{l}\mathrm{D} 1: 38 \% \\
\mathrm{~T} 2: 62 \%\end{array}$ \\
\hline 3 & 56 & 61 & 75 & 32 & 31 & D1 & - & - & $\mathrm{D} 2$ & $\mathrm{~T} 1$ & D1: $100 \%$ \\
\hline 4 & 33 & 26 & 6 & 5.3 & 0.2 & $\mathrm{~N}$ & $\mathrm{~N}$ & $\mathrm{~N}$ & $\mathrm{~T} 1$ & $\mathrm{~T} 1$ & $\begin{array}{l}\mathrm{N}: 46 \% \\
\mathrm{~T} 2: 44 \%\end{array}$ \\
\hline 5 & 176 & 205.9 & 47.7 & 75.7 & 68.7 & D1 & - & - & D1 & $\mathrm{T} 1$ & D1: $100 \%$ \\
\hline 6 & 70.4 & 69.5 & 28.9 & 241.2 & 10.4 & $\mathrm{~T} 3$ & - & - & $\mathrm{T} 3$ & T3 & $\begin{array}{l}\text { T2: } 37 \% \\
\text { T3: } 58 \% \\
\text { PD: } 21 \%\end{array}$ \\
\hline 7 & 162 & 35 & 5.6 & 30 & 44 & $\mathrm{D} 2$ & D2 & $\mathrm{D} 2$ & $\mathrm{D} 2$ & $\mathrm{D} 2$ & $\begin{array}{l}\text { D1: } 49 \% \\
\text { D2: } 30 \%\end{array}$ \\
\hline 8 & 345 & 112.25 & 27.5 & 51.5 & 58.75 & D1 & D1 & D2 & D2 & D1 & D1: 96\% \\
\hline 9 & 181 & 262 & 210 & 528 & 0 & $\mathrm{~T} 2$ & $\mathrm{~T} 2$ & $\mathrm{~T} 2$ & $\mathrm{~T} 3$ & $\mathrm{~T} 3$ & T2: $100 \%$ \\
\hline 10 & 172.9 & 334.1 & 172.9 & 812.5 & 37.7 & $\mathrm{~T} 3$ & $\mathrm{~T} 3$ & $\mathrm{~T} 3$ & $\mathrm{~T} 3$ & $\mathrm{~T} 3$ & $\begin{array}{l}\text { T2: } 44 \% \\
\text { T3: } 50 \%\end{array}$ \\
\hline 11 & 2587.2 & 7.882 & 4.704 & 1.4 & 0 & $\mathrm{PD}$ & $\mathrm{PD}$ & PD & $\mathrm{T} 1$ & S & PD: $100 \%$ \\
\hline 12 & 1678 & 652.9 & 80.7 & 1005.9 & 419.1 & D2 & D2 & - & DT & D2 & $\begin{array}{l}\text { D1: } 50 \% \\
\text { T3: } 41 \%\end{array}$ \\
\hline 13 & 206 & 198.9 & 74 & 612.7 & 15.1 & $\mathrm{~T} 3$ & - & - & $\mathrm{T} 3$ & T3 & $\begin{array}{l}\text { T2: } 39 \% \\
\text { T3: } 59 \% \\
\text { N: } 31 \%\end{array}$ \\
\hline 14 & 180 & 175 & 75 & 50 & 4 & $\mathrm{~T} 1$ & $\mathrm{~N}$ & $\mathrm{~N}$ & $\mathrm{~T} 2$ & $\mathrm{~T} 1$ & $\begin{array}{l}\text { T1: } 19 \% \\
\text { T2: } 49 \% \\
\text { D1: } 49 \%\end{array}$ \\
\hline 15 & 34.45 & 21.92 & 3.19 & 44.96 & 19.62 & $\mathrm{D} 2$ & D2 & - & DT & D2 & $\begin{array}{l}\text { D2: } 12 \% \\
\text { T3: } 38 \%\end{array}$ \\
\hline 16 & 51.2 & 37.6 & 5.1 & 52.8 & 51.6 & D2 & D2 & D2 & D2 & D2 & $\begin{array}{l}\text { D2: } 100 \% \\
\text { PD: } 19 \%\end{array}$ \\
\hline 17 & 106 & 24 & 4 & 28 & 37 & $\mathrm{D} 2$ & D2 & $\mathrm{D} 2$ & $\mathrm{D} 2$ & D2 & $\begin{array}{l}\text { D1: } 37 \% \\
\text { D2: } 44 \%\end{array}$ \\
\hline 18 & 180.85 & 0.574 & 0.234 & 0.188 & 0 & $\mathrm{PD}$ & PD & $\mathrm{PD}$ & $\mathrm{T} 2$ & PD & PD: $100 \%$ \\
\hline 19 & 27 & 90 & 42 & 63 & 0.2 & $\mathrm{~T} 2$ & $\mathrm{~T} 2$ & - & $\mathrm{T} 2$ & $\mathrm{~T} 2$ & $\mathrm{~T} 2: 100 \%$ \\
\hline 20 & 138.8 & 52.2 & 6.77 & 62.8 & 9.55 & D2 & D2 & - & $\mathrm{T} 3$ & D2 & $\begin{array}{l}\text { T2: } 21 \% \\
\text { T3: } 71 \%\end{array}$ \\
\hline
\end{tabular}

Table 9. Dataset from Long An PC (gas contents in ppm).

\begin{tabular}{|c|c|c|c|c|c|c|c|c|c|c|c|}
\hline Sample & $\mathbf{H}_{2}$ & $\mathrm{CH}_{4}$ & $\mathrm{C}_{2} \mathrm{H}_{6}$ & $\mathrm{C}_{2} \mathrm{H}_{4}$ & $\mathrm{C}_{2} \mathrm{H}_{2}$ & Known fault & IEC [5] & Rogers [4] & $\begin{array}{l}\text { Duval } \\
\text { triangle [8] }\end{array}$ & $\begin{array}{l}\text { Duval } \\
\text { pentagon }[10]\end{array}$ & $\begin{array}{l}\text { Proposed } \\
\text { method }\end{array}$ \\
\hline 1 & 23.6 & 12.4 & 3.8 & 50.9 & 0 & $\mathrm{~T} 3$ & N/A & $\mathrm{T} 2$ & $\mathrm{~T} 3$ & $\mathrm{~T} 3$ & $\begin{array}{l}\text { T3 }(30 \%) \\
\text { T3 }(70 \%)\end{array}$ \\
\hline 2 & 5.6 & 32.4 & 10.1 & 13.1 & 0 & $\mathrm{~T} 2$ & $\mathrm{~T} 2$ & $\mathrm{~N} / \mathrm{A}$ & $\mathrm{T} 2$ & $\mathrm{~T} 2$ & T2 (100\%) \\
\hline 3 & 43.3 & 50 & 8.9 & 11.2 & 0 & $\mathrm{~T} 2$ & $\mathrm{~T} 2$ & $\mathrm{~T} 2$ & $\mathrm{~T} 1$ & $\mathrm{~T} 1$ & T2 (99\%) \\
\hline 4 & 170.7 & 68.9 & 8.4 & 5.7 & 0 & PD & N/A & $\mathrm{N}$ & $\mathrm{T} 1$ & S & $\begin{array}{l}\mathrm{N}(50 \%) \\
\mathrm{PD}(44 \%)\end{array}$ \\
\hline 5 & 4.7 & 14.3 & 2 & 6 & 0 & $\mathrm{~T} 2$ & $\mathrm{~T} 3$ & $\mathrm{~T} 2$ & $\mathrm{~T} 2$ & $\mathrm{~T} 2$ & $\begin{array}{l}\text { T2 }(69 \%) \\
\text { T3 }(31 \%)\end{array}$ \\
\hline 6 & 5.7 & 14.7 & 2.1 & 5.8 & 0 & $\mathrm{~T} 2$ & $\mathrm{~T} 2$ & $\mathrm{~T} 2$ & $\mathrm{~T} 2$ & $\mathrm{~T} 2$ & $\begin{array}{l}\text { T2 }(90 \%) \\
\text { T3 }(10 \%)\end{array}$ \\
\hline 7 & 12.1 & 11.3 & 3.6 & 24.7 & 0 & $\mathrm{~T} 3$ & $\mathrm{~N} / \mathrm{A}$ & $\mathrm{T} 2$ & $\mathrm{~T} 3$ & $\mathrm{~T} 3$ & $\begin{array}{l}\text { T2 }(42 \%) \\
\text { T3 }(58 \%)\end{array}$ \\
\hline
\end{tabular}

\subsection{Inspection on a Larger Dataset}

The authors collected 240 samples from local utilities in the Southern region of Vietnam and performed multiple tests. The overall results are summarized in Table 10. In general, the proposed method generated highly reliable conclusions that agreed well with actual faults, with an accuracy of over $80 \%$.
Except for the Duval pentagon, none of the others can reach $50 \%$ accuracy in this dataset. A noteworthy feature of the proposed method is that it is more sensitive to partial discharge faults than other interpretation methods.

An online demo version of the method is also available for use. The IEC ratio, Roger ratio, Duval triangle, and pentagon are also included in this demo version; all of them are implemented using Javascript and HTML. However, the algorithm used for 
developing graphical-based methods in this online version is not very accurate when the point lies on the edge of a fault zone. A better choice would be using a more mathematical-oriented environment such as MATLAB or OCTAVE.

Table 10. Comparison of various methods over a large transformer fleet.

\begin{tabular}{|c|c|c|c|c|c|c|}
\hline \multirow{2}{*}{ Fault } & \multirow{2}{*}{ Actual case } & \multicolumn{5}{|c|}{ Number of correct diagnosis } \\
\hline & & IEC [5] & Rogers [4] & Duval triangle [8] & Duval pentagon [10] & Proposed method \\
\hline PD & 23 & 7 & 3 & 7 & 6 & 20 \\
\hline D1 & 32 & 6 & 1 & 22 & 20 & 24 \\
\hline D2 & 63 & 6 & 19 & 15 & 18 & 44 \\
\hline $\mathrm{T} 1$ & 76 & 44 & 68 & 35 & 74 & 65 \\
\hline $\mathrm{T} 2$ & 18 & 14 & 1 & 4 & 5 & 14 \\
\hline $\mathrm{T} 3$ & 28 & 20 & 5 & 28 & 28 & 28 \\
\hline Percentage & & $40 \%$ & $40 \%$ & $46 \%$ & $63 \%$ & $81 \%$ \\
\hline
\end{tabular}

\section{Conclusion}

In this paper, a new algorithm to detect potential faults inside power transformers was introduced. The diagnostic system is made based on fuzzy logic that process ratios and percentages of key gases obtain from DGA results. In most cases presented throughout the paper, the use of fuzzy logic overcomes the limitations of traditional gas ratios based interpretation with high accuracy in fault diagnosis. Since the method allows the detection of multiple faults in one sample, it can provide comprehensive insights into the conditions of a power transformer. That feature might provide additional information and help condition assessment be more reliable. The proposed diagnosis algorithm is not only efficient but also very simple to implement. In short, the research contributes a useful tool for the condition assessment of power transformers.

Nowadays, alarm concentration values are set by independent experts, based on previous experience with equipment with similar characteristics [5]. Future research on this topic should examine the fault criticality to determine the normality percentages and critical concentrations. Again, using fuzzy logic would be a suitable approach to this task, since gas concentrations can vary from sample to sample.

\section{Acknowledgements}

The authors would like to express gratitude toward the Oil Testing Lab at the Southern Electrical Testing Company for the data they provided.

\section{References}

[1] "IEEE Guide for Evaluation and Reconditioning of Liquid Immersed Power Transformers," in IEEE Std C57.140-2017 (Revision of IEEE Std C57.140-2006), 2017, doi: 10.1109/IEEESTD.2017.8106924.

[2] "IEEE Guide for Diagnostic Field Testing of Fluid-Filled Power Transformers, Regulators, and Reactors," in IEEE Std C57.152-2013, 2013, doi: 10.1109/IEEESTD.2013.6544533.

[3] "IEEE Guide for the Interpretation of Gases Generated in Mineral Oil-Immersed Transformers," in IEEE Std
C57.104-2019 (Revision of IEEE Std C57.104-2008), 2019, doi: 10.1109/IEEESTD.2019.8890040.

[4] R. R. Rogers, "IEEE and IEC Codes to Interpret Incipient Faults in Transformers, Using Gas in Oil Analysis," in IEEE Transactions on Electrical Insulation, vol. EI-13, no. 5, pp. 349-354, Oct. 1978, doi: 10.1109/TEI.1978.298141.

[5] "Mineral oil-filled electrical equipment in service - Guidance on the interpretation of dissolved and free gases analysis," in IEC 60599.

[6] S. Chakravorti, D. Dey, and B. Chatterjee, Recent trends in the condition monitoring of transformers theory, implementation and analysis. London: Springer, 2013.

[7] M. Duval and A. dePabla, "Interpretation of gas-in-oil analysis using new IEC publication 60599 and IEC TC 10 databases," in IEEE Electrical Insulation Magazine, vol. 17, no. 2, pp. 31-41, March-April 2001, doi: 10.1109/57.917529.

[8] M. Duval, "A review of faults detectable by gas-in-oil analysis in transformers," in IEEE Electrical Insulation Magazine, vol. 18, no. 3, pp. 8-17, May-June 2002, doi: 10.1109/MEI.2002.1014963.

[9] M. Duval, "The Duval triangle for load tap changers, non-mineral oils and low temperature faults in transformers," in IEEE Electrical Insulation Magazine, vol. 24, no. 6, pp. 22-29, November-December 2008, doi: 10.1109/MEI.2008.4665347.

[10] M. Duval and L. Lamarre, "The duval pentagon-a new complementary tool for the interpretation of dissolved gas analysis in transformers," in IEEE Electrical Insulation Magazine, vol. 30, no. 6, pp. 9-12, November-December 2014, doi: 10.1109/MEI.2014.6943428.

[11] B. M. Taha, S. S. M. Ghoneim and A. S. A. Duaywah, "Refining DGA methods of IEC Code and Rogers four ratios for transformer fault diagnosis," 2016 IEEE Power and Energy Society General Meeting (PESGM), 2016, pp. 1-5, doi: 10.1109/PESGM.2016.7741157.

[12] D. A. Mansour, "Development of a new graphical technique for dissolved gas analysis in power transformers based on the five combustible gases," in IEEE Transactions on Dielectrics and Electrical Insulation, vol. 22, no. 5, pp. 2507-2512, October 2015, doi: 10.1109/TDEI.2015.004999.

[13] E. Gouda, S. H. El-Hoshy, and H. H. El-Tamaly, "Proposed heptagon graph for DGA interpretation of oil transformers," IET Generation, Transmission \& Distribution, vol. 12, no. 2, pp. 490-498, 2018. 
[14] Hongzhong Ma, Zheng Li, P. Ju, Jingdong Han and Limin Zhang, "Diagnosis of power transformer faults on fuzzy three-ratio method," 2005 International Power Engineering Conference, 2005, 10.1109/IPEC.2005.206897.
[15] Mang-Hui Wang, "A novel extension method for transformer fault diagnosis," in IEEE Transactions on Power Delivery, vol. 18 , no. 1, pp. 164-169, Jan. 2003, doi: 10.1109/TPWRD.2002.803838. 